\title{
Assumption of Entrepreneurial Education Online Course-Exploration based on MOOC
}

\author{
Jian Chen, Hui Tao, Tao Wang \\ Zhejiang Pharmaceutical College, Ningbo Zhejiang, 315100, China
}

\begin{abstract}
Keywords: MOOC, Entrepreneurial Education, Online Course, Teaching Design, Interactive Classroom, Thought
\end{abstract}

\begin{abstract}
Nowadays, it is the times of mass business and innovations. Innovative entrepreneurship online course based on internet has already been successively developed in the society and educational organizations at all levels. With the hope of offering more entrepreneurial talents for the society, it can ease the huge employment pressure confronted by Chinese society at present. Based on the MOOC, this paper will make assumptions. After analyzing its basic theory and innovations, it will establish entrepreneurial education online courses for Chinese colleges and universities centering on MOOC educational mode, so as to realize the innovative entrepreneurial purpose.
\end{abstract}

\section{Introduction}

MOOC is called as the "tsunami" of modern educational circle. Its openness, education and service application have already been recognized by the modern society and educational field. It gives powerful impact on the traditional educational mode, which brings unlimited opportunities and challenges to development of all social industries. In term of entrepreneurial education, current colleges and universities are still lack of novelty and scientific practicability during the pioneering and popularizing progress. MOOC put forward in this paper can achieve the organic integration of online self-learning and offline classroom teaching, which will become the mainstream pattern of entrepreneurial education of colleges and universities in the future.

\section{Educational Mode of MOOC}

\section{Connotations of MOOC}

MOOC refers to the Massive Open Online Courses, which are geared to all learners for free. In China, MOOC has no specific definitions. However, from the practical nature of MOOC in recent years, it possesses the teaching mode of free registration, openness, large-scale, network-based and resource sharing. Such a mode takes full advantage of the social network and realizes the online communication and real-time guidance of teaching activity, which stimulates the self-learning initiative and exploration of knowledge of learners, further to let learner improve the teaching quality and utilization efficiency of resources. For the learning type, it is one kind of improvement and enrichment.

\section{Characteristics of MOOC}

MOOC has emerged in the times of internet. As the reason why it can sweep around the global educational fields within quite a short time, that's because it can satisfy the modern educational filed' and people's realistic requirements of educational innovation and knowledge absorption, and also greatly enrich all kinds of shortcomings of the traditional advanced education. Except for the above characteristics, MOOC has still paid attention to the strengthening role in teaching organization and learning effect evaluation and certification. It has realized the regression from online multimedia to traditional classroom teaching.

Secondly, MOOC can offer free resources, so as to realize the whole participation in the teaching progress and support the most complete teaching service. From preparation before class to result certification, MOOC starts well and ends well. Generally speaking, the online courses offered by MOOC last for two to three months. Colleges and universities can totally integrate MOOC with curriculums of that semester. After registering all courses within specific time, they can develop 
MOOC online courses for students in the form of traditional classroom. Compared to traditional classrooms, it is more effective and convenient for schools to complete the teaching of curriculums. Therefore, high-quality teaching resources of colleges and universities can be totally shared.

Moreover, MOOC are short and precise. For university students, a long big class must lead students' attention to decline, who cannot concentrate their attentions. Multimedia courses offered by MOOC only last for 10 to 20 minutes. Knowledge points are summarized and refined. One chapter lasts for 10 to 20 minutes. Courses are promoted one by one, so as to realize the segmentation of knowledge points. Therefore, people also call MOOC as the "micro-course" of modern education. Such a course taking single knowledge point as the unit cannot only concentrate attentions of students, but also bring more fun based on multimedia to students. Such as the classroom integrated with PPT, teacher feature, demonstration on electron plate, all these can guarantee the intuitiveness, freshness and timeliness of teaching. Therefore, MOOC online education of colleges and universities belongs to rich media education. Rich learning contents created and shared by MOOC are active and vivid, which can help students to memory, think and understand more effectively. It is a real course mode of bilateral interaction + guidance.

Finally, MOOC has still offered the interactive online evaluation mode among students, which not only realizes mutual evaluation, but also achieves the goal of mutual learning. For teachers, such interactive evaluation among students fully resolves the burden of large-scale homework correcting. It can be seen that, just because of the above characteristics of MOOC, it is different from the traditional network course, but more independent and innovative, further to set up unique teaching environment for learners. In Time, a famous American magazine, it just evaluates MOOC like this "MOOC opens a door leading to The Ivy League for everyone, which plays crucial influence on the development of advanced education. ${ }^{[1],}$

\section{Thought and Innovations of Entrepreneurial Education MOOC Platform Construction}

\section{Construction Thought \\ Cloud Computing}

Just as MOOC, cloud computing is the product of the Internet Era, which unfolds the boom of Third IT Revolution for PC internet and thoroughly announces the arrival of network information service age at low costs but with super values. Meanwhile, it has also brought new revolution and unprecedented opportunities for the social employment and entrepreneurial development. In the platform of cloud computing, its featured technologies have widely penetrated into the current application of commercial society fields, including cloud storage, cloud security and cloud motion.

Targeted at the entrepreneurial education, cloud applications can offer diversified information technology services for college teachers and students. It well conforms to the perfect implementation of colleges' entrepreneurial education in MOOC, meanwhile, it also cuts down the training of teachers' information technology. Thus colleges and universities have larger space for carrying out the entrepreneurial education. High security offered by the cloud platform also offers a quite good teaching atmosphere for the individual play of MOOC online entrepreneurial education, opens a new path for teachers' effective teaching and students' subjective and coordinated learning, promotes the cultivation of students' advanced thinking ability and collective wisdom ability, so as to let quality of online courses of entrepreneurial education based on MOOC to be better.

Smart MOOC Platform Technology

Nowadays, entrepreneurial education of colleges and universities have adopted the new generation MOOC information technology, which is the technological social network based on computer and Internet of Things. Of which, there are comprehensively integrated tools of Fab, Living Lab and related technological applications. These technologies have effectively innovated the new ecology of MOOC entrepreneurial education and realized the full appreciation of the changes of social situations. In addition, smart MOOC platform has offered one popular and coordinated innovation ides for wide learners, which emphasizes on setting and practice of virtual simulation environment and allows learners to complete the entrepreneurial educational task in the open online state. Meanwhile, it supports defined practical strategies and result evaluations, which is a comprehensive and extremely 
feasible supervision, counseling and management mode for the contemporary entrepreneurial education in colleges and universities.

Generally speaking, online courses of entrepreneurial education based on MOOC widely explore all advanced technologies of the contemporary Internet Era, which integrates several information resources, including cloud computing and smart virtual information, so as to realize the optimization of entrepreneurial educational courses. Finally, it will become the sharing mechanism resource communication with the largest scope and highest efficiency, further to create a perfect and systematic online entrepreneurial educational platform.

\section{Innovations}

Integration of Education and Information Technology

As described above, entrepreneurial education MOOC online mode has integrated the cloud computing technology, embedded technology, Internet of Things technology, cloud extracting technology, network communication technology, modern encryption algorithms, SAAS software service, PAAS platform service and DAAS desktop service technology, etc. Integration of these technologies has changed the way how entrepreneurs apply and interact with the educational resources. Cooperation and coordination can be fatherly highlighted. On the basis of integration, it has also improved the informatization level of entrepreneurial education.

Solving the Problem of Information Isolated Island

MOOC platform has offered more network accesses and open network interfaces for the entrepreneurial educational courses of colleges and universities. According to the unified information standard, it transmits and sends out data, helps the online platform to realize the multiple integration of heterogeneous data source and different management mechanism data, further to let the MOOC platform to be more unified, perfect, standard and sharing. It solves the isolated island effect existing in traditional network teaching. Due to the stronger nature of business and data integration service, it basically satisfies learner's any requirement about the MOOC platform in network.

Breaking Through the Limitations of Teaching Space and Time

On the entrepreneurial educational MOOC platform, massive amounts of educational resources and service information are controlled and managed by unification. Relying on OC and mobile terminals, learners can have access to the internet, learn wherever and whenever, search resources and enjoy educational services brought by MOOC platform. As university students who wish to realize the dream of entrepreneurship, MOOC entrepreneurial educational courses do not require them to master too complicated software, which lower the educational threshold, realize the same intimacy with the offline courses and improve the learners' learning productivity and initiative, and then achieve the goal of improving learning effects whenever and wherever at last [2].

\section{Entrepreneurial Education Online Course Platform Design Based on Smart Tree MOOC}

\section{Introduction of Smart Tree MOOC Platform}

Smart Tree MOOC Platform is the largest online educational course platform in China. On the basis of "people come first", it develops online spontaneous learning and discussion, and also leap-forward large classroom live interactions. Meanwhile, it also supports credit certification and diploma support, which is an excellent educational platform assisting the alliance and schools in completing high-quality educational resource sharing. Since the establishment of smart tree MOOC platform, it has already cooperated with 200 universities, covered nearly 3 million university students and helped universities and colleges to realize reform of traditional teaching methods and qualities, especially the construction and implementation of entrepreneurial educational online course for university students.

\section{Smart Tree MOOC Online Interactive Classroom}

On the smart tree MOOC platform, online interactive classroom offers the real-time online course resource application, examinations and online problem solution. On the teaching management layer, it mainly includes functions of lesson preparation, assisted teaching, online examination, analysis on teaching effect, group teaching and advanced learning; in the aspect of teaching resources, it mainly covers teaching videos, audios, image-text, PPT and Flash, and also allows teachers and students to 
upload and download resources they need; in addition, there are exercise database, where teachers can create exercises for students and search questions of other schools. Students can also make classification retrieval of exercises, such as choice question, True or False, essay question, etc. Teachers can alter the difficulty coefficient targeted at the exercises and put forward different learning requirements for students.

\section{Foundations of Entrepreneurship Online Entrepreneurial Educational Course Design based on MOOC Pattern}

Based on MOOC pattern, it designs online entrepreneurial educational course for colleges and universities. Dominated by the course of Foundations of Entrepreneurship, this paper shall design corresponding MOOC entrepreneurial educational online course from the perspective of entrepreneurial spirit, team, opportunity, risk, resources and planning, and also establishment of new enterprises. Basic concept of this course design takes "learning-oriented" constructivism as the teaching theory and design philosophy, put forwards the learning-oriented teaching design concept and classifies the online courses into four steps, respectively are objective design, situation establishment and exercise design.

Design of Teaching Objective

Currently, Foundations of Entrepreneurship is the compulsory course of entrepreneurial education in some Chinese colleges and universities, which requires students to master certain entrepreneurial skills and specify notices of entrepreneurship. This paper designs that on the MOOC platform of smart tree, realizes the online learning environment of entrepreneurial education on the MOOC network platform for students, and also offers instructive learning suggestions for students through the mode of MOOC.

Design of Teaching Situation

During the MOOC online course design of Foundations of Entrepreneurship, the preface is set as the video case of entrepreneurship, so as to let students watch those videos and understand related events of entrepreneurial winners. By integrating the theoretical knowledge of entrepreneurship with video cases, teachers can interpret the entrepreneurial knowledge for students, which is good for them to better understand the contents of entrepreneurial education. The teaching efficiency shall be improved more or less. For instance, by adding the videos of successful entrepreneurs before the course of Foundations of Entrepreneurship, it will lead students to enter the online teaching situation, such as Xi Shi of Squid and Story of Kai-Fu Lee.

Design of Teaching Evaluation

In the mode of MOOC, teaching evaluation is mainly divided into two classifications: formative evaluation and summative evaluation. On the online course of Foundations of Entrepreneurship, the formative evaluation will be implemented on students firstly. According to the number of students' logging in the MOOC platform, learning time and enthusiasm of forum discussion, it will form the formative evaluation. After every chapter of Foundations of Entrepreneurship is completed, MOOC will make a summative evaluation on students. In the middle and end of the semester, students complete and submit the exercises given by the MOOC platform within the required time. Thus they complete the entrepreneurial educational examination based on MOOC platform. After the examination, the platform will make a summative evaluation about students ${ }^{[3]}$.

\section{Conclusion}

MOOC platform offers online course mode without the limitations of time or space for learners participating in entrepreneurial education, which realizes the construction of learning-oriented society and promotes the development progress of information technology. Nowadays, in the new internet + times pursuing innovation and entrepreneurship, all people are consistently trying to expand resources, forming clustering, sharing, promotion and pushing function of resources, so as to solve the unfair social development caused by uneven educational resources. Construction of MOOC platform and promotion of entrepreneurial education online course is just such an ideal mode with balanced educational resources, which is worth us to consistently make deep explorations. 


\section{Acknowledgments}

This paper is the subject of Ningbo colleges and universities ideological and political education seminar, title: Researches on Ideological and Political Education of College Students from the Perspective of Entrepreneurial Education, No. SGXSZ14012.

\section{References}

[1] Li Yun, Lin Zhuliang, Wang Zewen. Measures to Improve the Higher Vocational Educational Quality based on MOOC. Communication of Vocational Education, 2015,(4):56-60.

[2] Zhu Yankong, Chu Hanfang. Constructions and Explorations of Entrepreneurial Education MOOC Platform. Experimental Technology and Management, 2014,31(9):170-172.

[3] Qian Huibo. Researches on MOOC Curriculum Design Model of Open Universities. Shanghai Normal University, 2015.8-15. 